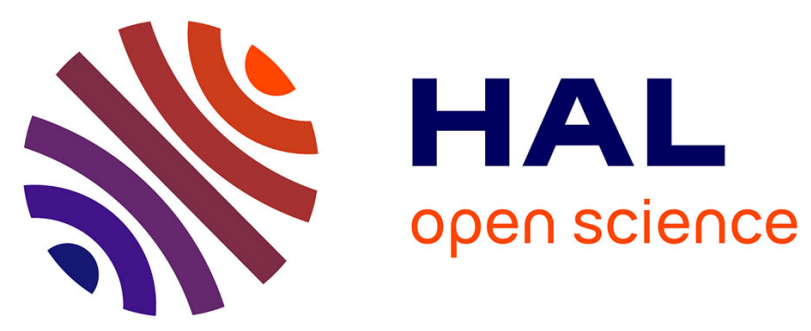

\title{
General Analytical Model of Magnet Average Eddy-Current Volume Losses for Comparison of Multi-phase PM Machines with Concentrated Winding
}

Bassel Aslan, Eric Semail, Jerôme Legranger

\section{- To cite this version:}

Bassel Aslan, Eric Semail, Jerôme Legranger. General Analytical Model of Magnet Average EddyCurrent Volume Losses for Comparison of Multi-phase PM Machines with Concentrated Winding. General Analytical Model of Magnet Average Eddy-Current Volume Losses for Comparison of Multiphase PM Machines with Concentrated Winding, 2014, 29 (1), pp.72-83. 10.1109/TEC.2013.2292797 . hal-01009626

\section{HAL Id: hal-01009626 \\ https://hal.science/hal-01009626}

Submitted on 3 Jul 2014

HAL is a multi-disciplinary open access archive for the deposit and dissemination of scientific research documents, whether they are published or not. The documents may come from teaching and research institutions in France or abroad, or from public or private research centers.
L'archive ouverte pluridisciplinaire HAL, est destinée au dépôt et à la diffusion de documents scientifiques de niveau recherche, publiés ou non, émanant des établissements d'enseignement et de recherche français ou étrangers, des laboratoires publics ou privés. 


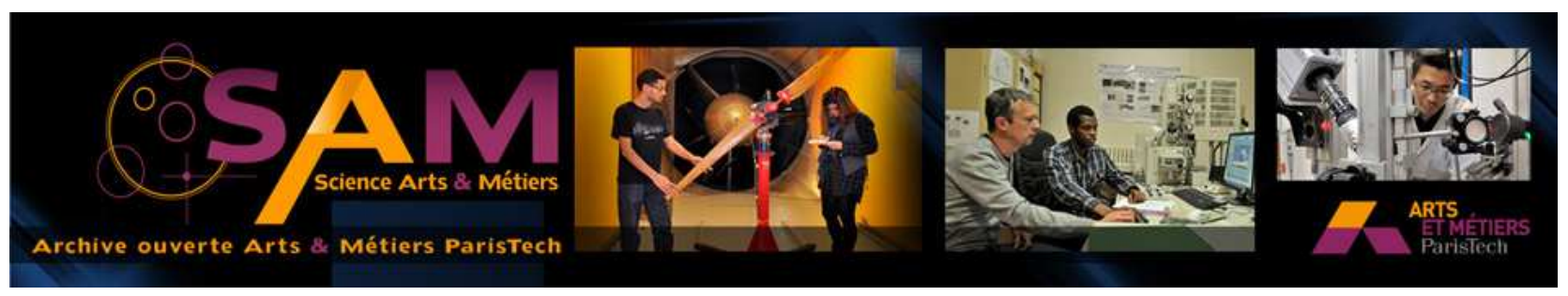

\section{Science Arts \& Métiers (SAM)}

is an open access repository that collects the work of Arts et Métiers ParisTech researchers and makes it freely available over the web where possible.

This is an author-deposited version published in: http://sam.ensam.eu

Handle ID: .http://hdl.handle.net/10985/8268

\section{To cite this version :}

Bassel ASLAN, Eric SEMAIL, Jerome LEGRANGER - General Analytical Model of Magnet Average Eddy-Current Volume Losses for Comparison of Multi-phase PM Machines with Concentrated Winding - General Analytical Model of Magnet Average Eddy-Current Volume Losses for Comparison of Multi-phase PM Machines with Concentrated Winding - Vol. 29, n¹, p.72-83 - 2014 


\title{
General Analytical Model of Magnet Average Eddy-Current Volume Losses for Comparison of Multi-phase PM Machines with Concentrated Winding
}

\author{
Bassel Aslan, Student member, IEEE, Eric Semail, member, IEEE, and Jerome Legranger
}

\begin{abstract}
- this paper studies magnet eddy-current losses in permanent magnet (PM) machines with concentrated winding. First of all, space harmonics of magnetomotive force (MMF) and their influence on magnet losses in electrical machines are investigated. Secondly, analytical model of magnet volume losses is developed by studying the interaction between MMF harmonics wavelengths and magnet pole dimensions. Different cases of this interaction are exhibited according to the ratio between each harmonic wavelength and magnet pole width. Then various losses sub-models are deduced. Using this analytical model, magnet volume losses for many Slots/Poles combinations of 3, 5, and 7 phase machines with concentrated winding are compared. This comparison leads to classify combinations into different families depending on their magnet losses level. Finally, in order to verify the theoretical study, Finite Element models are built and simulation results are compared with analytical calculations.
\end{abstract}

Keywords-Concentrated Winding, Eddy-Current, Volume Magnet Losses, Multiphase Machine, Automotive, MMF, Spatial Harmonics, traction

\section{INTRODUCTION}

Nowadays Permanent Magnet motors (PM) with fractional-slot concentrated winding are becoming a preferred choice for automotive applications, due to their high torque/volume ratio, high efficiency, and simple structure which means easy manufacturing, maintenance, and recycling [1]-[2]. The main problem with machines of fractional-slot concentrated winding is the existence of parasitic effects [3] which in certain cases might be unbearable because of unbalanced mechanical structure and/or high eddy-current magnet rotor losses [4]. Therefore, many researches have proposed a classification of this kind of machines in order to help the designer to avoid bad choice of Slots/Poles combination [5]-[6]-[7]. These classifications are mainly based on rotor global losses with and without copper cladding.

Manuscript received December 20, 2012. This work was supported by ADEME and Valeo through MHYGALE project.

B. Aslan \& E. Semail are with the Laboratory of Electrical Engineering and Power Electronics of Lille L2ep at Arts et Metiers Paristech, Lille, 8 Bd Louis XIV 59043 France (phone: +33-6 1087 55 51; e-mail1: bassel.aslan@valeo.com, email2: eric.semail@ensam.eu).

J. legranger is with Valeo, Créteil, 2 rue André Boulle 94000 France (e-mail: jerome.legranger@valeo.com).
The purpose of the paper is to provide for high speed machines a classification based only on a general analytical approach of eddy-current rotor magnet losses. The interest of such classification is due to the fact that rotor permanent magnets cannot be heavily segmented as it is the case for electrical steel. Hence, rotor magnet eddy-current losses become one of the most critical subjects in electrical machines at high speeds. These losses can extremely heat magnets until causing permanent demagnetization which leads to full breakdown in the machine functionality [8]. Some studies have been done regarding the effect of MMF asynchronous spatial harmonics on rotor losses in synchronous machines [6]-[9]-[10]. The results show that some Slots/Poles combinations of concentrated winding machines create undesired MMF spatial spectrum of harmonics which can induce high level of rotor losses. These studies are based on analytical resolution of Maxwell equations (calculation of magnetic vector potential $A$ ) in order to calculate eddycurrent magnet losses [4]-[11]. As the equations are complex, they are solved each time for a specific structure. As consequence, it is difficult to deduce general tendencies for the designer. Besides, the precision of the results is depending on the degree of validity of assumptions used for the resolution of the equations.

Another calculation point of view is presented in few papers depending on traditional eddy-current elementary paths division [12]-[13]. Thus, simple models of magnet volume losses are deduced but always without taking into account the various MMF spatial harmonic wavelengths that result from concentrated winding structure.

Therefore, by considering the same kind of calculation used in [12]-[13] the present paper is concerned by the following investigation: how wavelengths of MMF spatial harmonics in the air gap interact with rotor magnet pole dimensions, causing different levels of magnet losses?

The objective of this paper is not to determine precisely the amount of magnet losses for each particular machine, but rather to develop a tool which ensures a precise comparison of magnet losses between generic machines taking into account their winding topologies.

The first part of this paper explains the different natures of MMF harmonics in the air gap depending on their wavelengths (harmonics, sub-harmonics) or their 
relative spatial propagation speeds according to the rotor. In the second part analytical formulations of magnet volume losses are developed considering various models of eddy-current paths in the magnet pole which result from several ways of harmonicmagnet interaction. Hence, for all MMF harmonics orders, different sub-models of magnet volume losses are built in order to represent different shapes of induced eddy-current circuits. In this part, it is shown also how these shapes vary according to the ratio between harmonic wavelength and magnet pole width.

The third part of paper uses the developed analytical model in order to compare magnet losses in different Slots/Poles combinations of 3, 5 and 7-phase machines. This comparison is done considering only winding topologies (MMF harmonics) and magnet pole dimensions. Besides, Finite Elements models for some combinations are built in order to validate the analytical comparison.

\section{Magnet losses theory}

In classical integral-slot winding machines, MMF has $p$ regular repeated forms and its parasitic spatial harmonics in the air gap are multiples of the fundamental one.

$\lambda_{v}=\frac{2 \cdot \pi \cdot R_{\text {rotor }}}{v}$

$v=(2 k+1) p \Rightarrow \lambda_{v}=\frac{\lambda_{\text {fund }}}{2 k+1}$

$\lambda_{\text {fund }}=\lambda_{p}, k \in I N ; R_{\text {rotor }}:$ radius of rotor

$p$ :number of poles pairs; $v$ :harmonic order

$\lambda_{v}$ :wavelength of the harmonic $v$

However, in the case of fractional-slot concentrated winding, MMF can contain parasitic spatial harmonics with various orders which may be close to the fundamental or even lower (called subharmonics) Fig. 1 (a) [14]:

- Harmonics close to the fundamental

$$
p<v<2 p \Leftrightarrow \frac{\lambda_{p}}{2}<\lambda_{v}<\lambda_{p}
$$

- Sub-harmonics

$$
v<p \Leftrightarrow \lambda_{v}>\lambda_{p}
$$

The fact that concentrated winding machines are accompanied with such MMF harmonics nominates these harmonics as the main suspect of causing high magnet losses. MMF parasitic harmonics rotate in the air gap with different speeds $\left(V_{v}\right)$ inducing currents in rotor magnet blocks and causing magnet losses [6]. Magnet flux density variation resulting from stator teeth can also produce certain amount of magnet losses (called usually slotting effect) [15]-[16]. However, this kind of losses depends mainly on the structure (teethslots shape) and generally it has less importance at high speeds, where crossing magnetic flux between stator and rotor is highly reduced by flux weakening procedure. Thus, in this paper only losses caused by MMF parasitic harmonics are considered.

Each MMF harmonic has three characteristics which can mainly affect losses level:

$>$ the amplitude which decides the related magnetic flux density in the air gap;

$>$ the relative speed in the air gap $\left(V_{v}\right)_{r}$ with respect to the rotor;

the wavelength.

MMF fundamental harmonic advances in the air gap with a zero relative $\operatorname{speed}\left(V_{p}=V_{\text {rotor }}\right)$, while other parasitic harmonics have different relative speeds $\left(V_{v}\right)_{r}$. These moving MMF harmonics create rotating flux density distribution of different wavelengths in the air gap (see Fig. 1). Consequently, by considering a reference point in rotor magnet blocks, the frequency of magnetic flux density $f_{B_{V}}$ resulting from the rotating harmonic $v$ can be calculated [9]:

$$
\begin{aligned}
& \left(V_{v}\right)_{r}=\left|V_{p}-\operatorname{sgn} \cdot V_{v}\right|=V_{v}\left|\frac{v}{p}-\operatorname{sgn}\right| \\
& f_{B_{V}}=\frac{\left(V_{v}\right)_{r}}{\lambda_{v}}=f_{\text {rotor }} p\left|\frac{v}{p}-\operatorname{sgn}\right|
\end{aligned}
$$

$f_{\text {rotor }}:$ rotor speed (turn/sec)

sgn : rotating direction of harmonic $v$

In Surface-Mounted PM machine (SPM) the same rotating distributions of flux density which are imposed by MMF harmonics in the air gap, are also applied directly on magnet blocks. Consequently, these blocks see almost the same distribution wavelengths as in the air gap Fig. 1 (b). While, in the case of Interior PM Machine (IPM), the wavelengths of flux distributions which are seen by magnets are multiplied by certain ratio due to the flux concentration structure.

This paper is interested in studying magnet losses caused by the interaction between flux density wavelengths $\lambda_{v}$ and magnet pole dimensions $(l, w, e)$ (see Fig. 1 (b)). Hence, magnet poles are considered as electrically isolated blocks, which is generally true in electrical machines. 


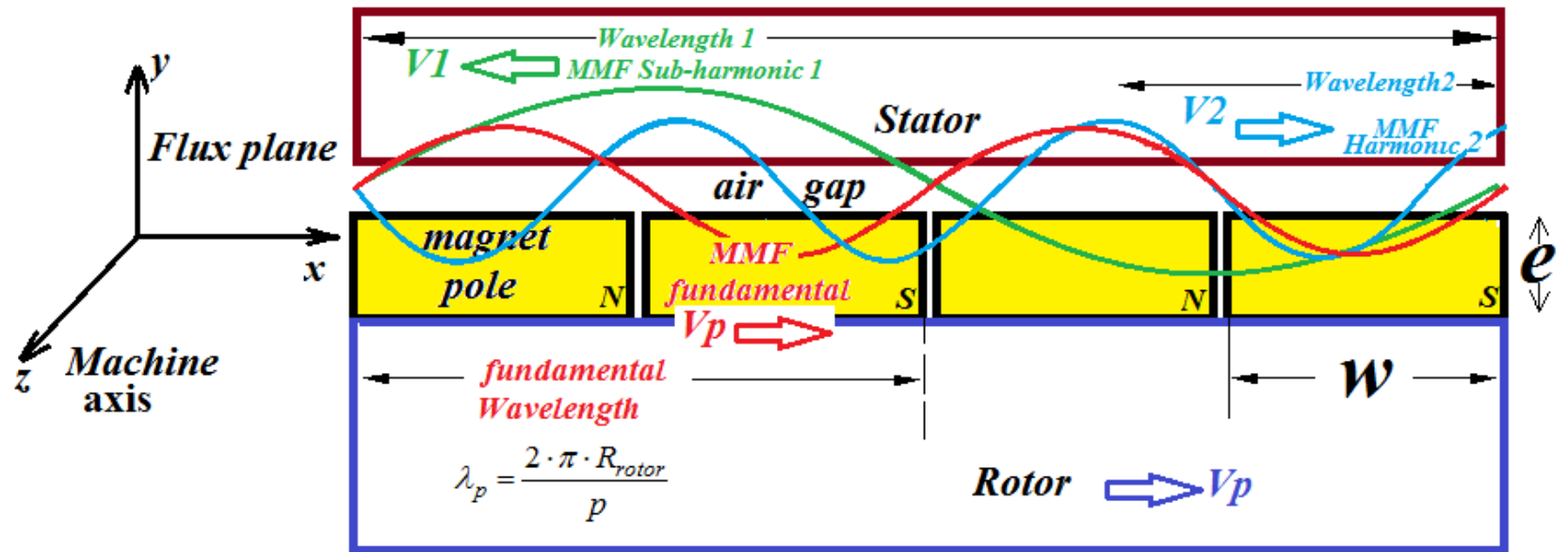

(a): Representative example of moving MMFs in the air gap of surface-mounted permanent magnet radial flux machine for different space harmonics, Vp being the speed of the rotor and of the MMF fundamental, V1 and V2 the speeds of two harmonic MMF

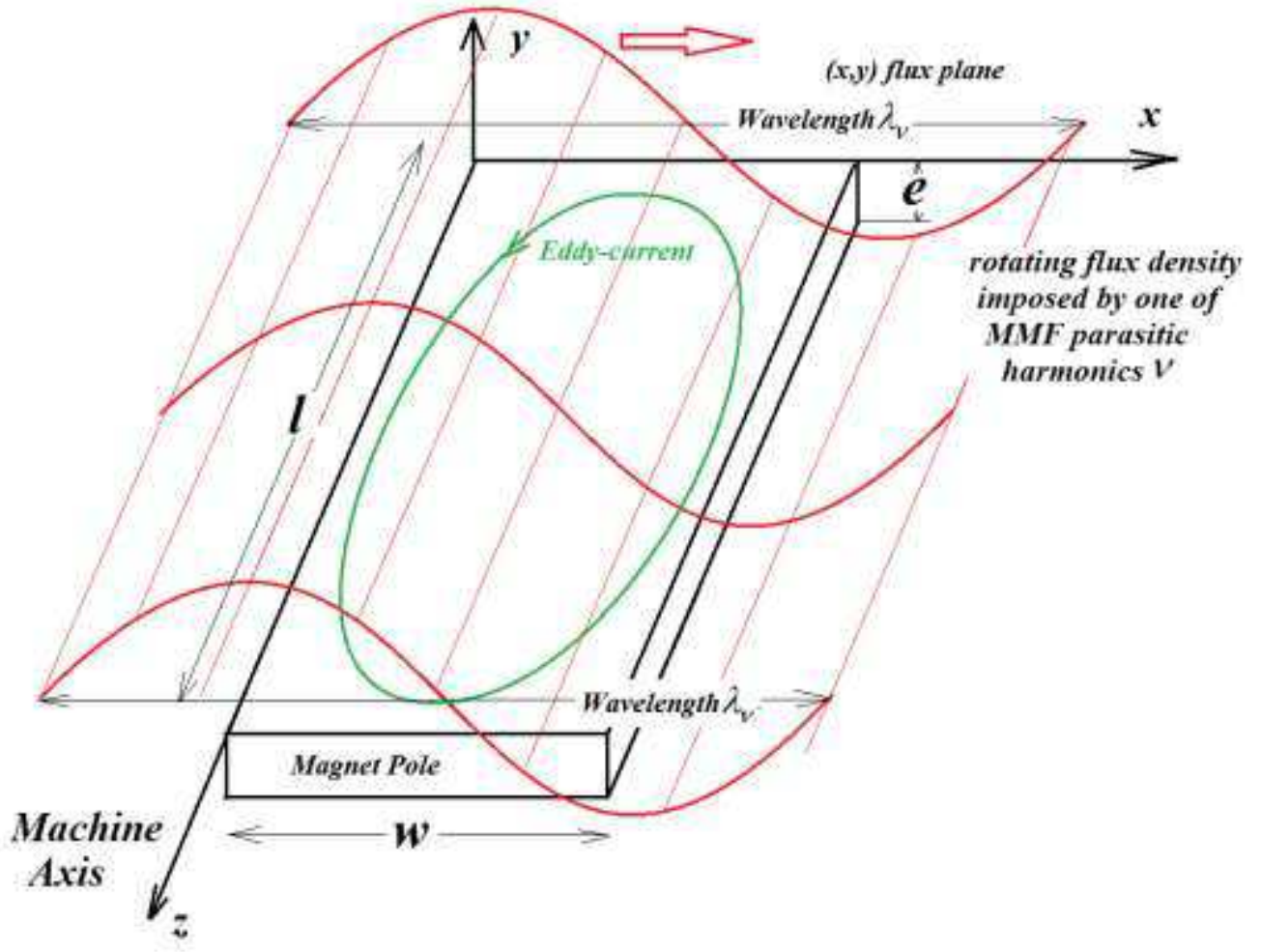

(b): Eddy-currents induced in a magnet pole by one of MMF parasitic harmonics

Fig. 1 MMF space harmonics applied on magnet poles in PM machines

III. Analytical model of magnet volume losses

Magnets in PM electrical machines are the only big not segmented conductors in the rotor. This makes them perfect targets of MMF parasitic harmonics which induce long circuits of eddy-currents in them.

In this paragraph various eddy-currents paths in magnets are proposed according to MMF-magnet interaction. Joule losses caused by these currents are then calculated. In order to simplify losses model calculations some assumptions are imposed:

- Magnet losses resulting from hysteresis and slotting effect are not considered in this analytical model, but only magnet losses generated by MMF parasitic harmonics are considered. Obviously, at high speed where much more magnet losses can be generated, slotting effect becomes less important due to flux weakening procedure.

- Magnet losses are the sum of losses caused by each sinusoidal rotating distribution of flux density $B_{v}$ with a wavelength $\lambda_{v}$ resulting from the MMF parasitic harmonic of the $\operatorname{order} v$.

- Flux density variation according to magnet thickness $(e)$ and length $(l)$ is neglected. 
- Iron saturation and skin effect phenomenon are not taken into account.

Finally, in order to make a fair comparison, magnet volume losses $P_{v o l}=($ Lost Power/Volume $)$ are calculated in the model.

Next paragraph shows that, the configuration of paths taken by eddy-currents in magnet block depends on the ratio between the wavelength $\lambda_{v}$ of MMF parasitic harmonic (which induces these currents) and magnet block width $w$. The four different situations of interaction between magnet pole width and MMF harmonic wavelength are illustrated in Fig 2 and associated calculus is developed in the four following paragraphs.
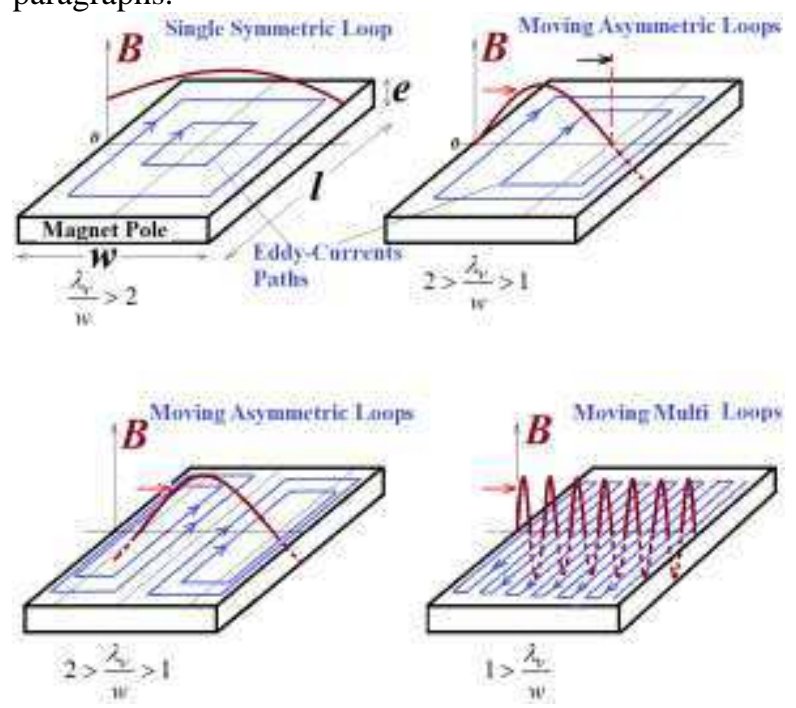

Fig. 2 different paths of eddy-current circuits according MMF wavelength and magnet width

A. Case with $\frac{\lambda_{v}}{w}>2$

If the wavelength $\left(\lambda_{v}\right)$ of flux density distribution resulting from an MMF parasitic harmonic $(v)$ is longer than twice magnet width $(2 \times w)$, the phase difference of flux density between two points along the magnet width is always less than $180^{\circ}$. Consequently, induced current densities cross the magnet plan (width $w$, thickness $e$ ) with a phase shift lower than $180^{\circ}$. Nevertheless, the fact that magnet blocks are electrically isolated forces the induced current to circulate back forming a single symmetric eddy-current loop as it is shown in Fig. 3 (a). In order to validate the supposed current paths configurations, 2D finite elements models similar to SPM machines are built. In these models constant current with certain winding topologies in stators allow creating MMF in the air gap with a single dominant constant harmonic, while relative speed of magnets according to this harmonic is ensured due to constant rotor velocity.
Since 2D models are used, the effect of current looping back in each magnet block should be compensated by imposing on current density $J$ :

$$
\iint_{2 D \text { magnet surface }} J(x, z) d x d z=0
$$

The result of finite elements simulation when $\lambda_{v} / w>2$ is illustrated in fig.3 (b) where it can be observed only one mode with single symmetric loop of eddy-currents taking place through time. As well, other instants of time with zero eddy-currents can be noticed.

Magnetic flux captured by one elementary eddycurrent path $(X, Y)$ can be written:

$$
\begin{aligned}
& \Phi_{e}=\int_{-X}^{X} B_{v}(x, t) \cdot d s: d s=2 \cdot \alpha \cdot X \cdot d x \\
& B_{v}(x, t)=B_{v} \cdot \sin \left(\omega_{v} t+\frac{2 \pi}{\lambda_{v}} x\right), \alpha=\frac{Y}{X}=\frac{l}{w} \Rightarrow \\
& \Phi_{e}(X, t)=\frac{2 \cdot \alpha \cdot X \cdot B_{v} \cdot \lambda_{v}}{\pi} \sin \left(\frac{2 \pi}{\lambda_{v}} X\right) \sin (\omega t)
\end{aligned}
$$

$\Phi_{e}$ : magnetic flux through elementary path

$B_{v}:$ flux density amplitude of MMF harmonic $v$

$\omega_{v}$ : flux density pulsation in magnets $=2 \cdot \pi \cdot f_{B v}$

$l$ : magnet pole length, $w$ : magnet pole width

Electrical resistance of an elementary current path $R_{e}$ is calculated:

$R_{e}=\rho \frac{4 Y}{e d X}+\rho \frac{4 X}{e d Y}=\frac{4 \cdot \rho \cdot X\left(\alpha^{2}+1\right)}{e \cdot \alpha \cdot d X}$

$\rho:$ magnet material resistivity

$e$ : magnet pole thickness

Joule losses in an elementary current path can be written:

$$
d P_{e}=\frac{\left(\frac{\partial \Phi_{e}(X, t)}{\partial t}\right)^{2}}{R_{e}} \quad \begin{aligned}
& d P_{e}=\frac{\alpha^{3} \cdot e \cdot B_{v}{ }^{2} \cdot \omega_{v}{ }^{2} \cdot \lambda_{v}{ }^{2} \cdot X}{\pi^{2} \rho\left(\alpha^{2}+1\right)} \times \\
& \sin ^{2}\left(\frac{2 \pi}{\lambda_{v}} X\right) \cdot \cos ^{2}\left(\omega_{v} t\right) \cdot d X
\end{aligned}
$$

The factor $\cos ^{2}\left(\omega_{v} t\right)$ does not depend on $\mathrm{X}$, which means that Joule losses pass simultaneously by zero in each elementary path. As a result, when $\lambda_{v} / w>2$ magnet pole losses become zero at least twice in the period $T_{B V}=1 / f_{B V}$ (see Fig. 3 (b)) and the mean value of Joule losses in an elementary path will be:

$$
\begin{aligned}
\left\langle d P_{e}\right\rangle & =\frac{2}{T_{B V}} \int_{0}^{\frac{T_{B V}}{2}}\left(d P_{e}\right) d t \\
& =\frac{\alpha^{3} \cdot e \cdot B_{v}{ }^{2} \cdot \omega_{v}{ }^{2} \cdot \lambda_{v}{ }^{2}}{2 \cdot \pi^{2} \rho \cdot\left(\alpha^{2}+1\right)} \cdot X \cdot \sin ^{2}\left(\frac{2 \pi}{\lambda_{v}} X\right) \cdot d X
\end{aligned}
$$

Finally, magnet volume losses caused by an MMF 
parasitic harmonic $v$ are calculated in the case $(\mathrm{A})$ :

$$
\begin{aligned}
& {\left[\left(P_{\text {vol }}\right)_{v}\right]_{a}=\frac{\int_{0}^{\frac{w}{2}}\left\langle d P_{e}\right\rangle}{\text { magnet pole volume }}=\frac{\int_{0}^{\frac{w}{2}}\left\langle d P_{e}\right\rangle}{e \cdot \alpha \cdot w^{2}}} \\
& {\left[\left(P_{v o l}\right)_{v}\right]_{a}=\frac{\alpha^{2} B_{v}{ }^{2} \omega_{v}{ }^{2}}{2 \cdot \pi^{2} \rho\left(\alpha^{2}+1\right)} \times} \\
& {\left[\frac{\lambda_{v}{ }^{2}}{16}+\frac{\lambda_{v}{ }^{4}}{32 \cdot \pi^{2} w^{2}}\left(1-\cos \left(\frac{2 \pi}{\lambda_{v}} w\right)\right)-\frac{\lambda_{v}{ }^{3}}{16 \cdot \pi \cdot w} \sin \left(\frac{2 \pi}{\lambda_{v}} w\right)\right]}
\end{aligned}
$$

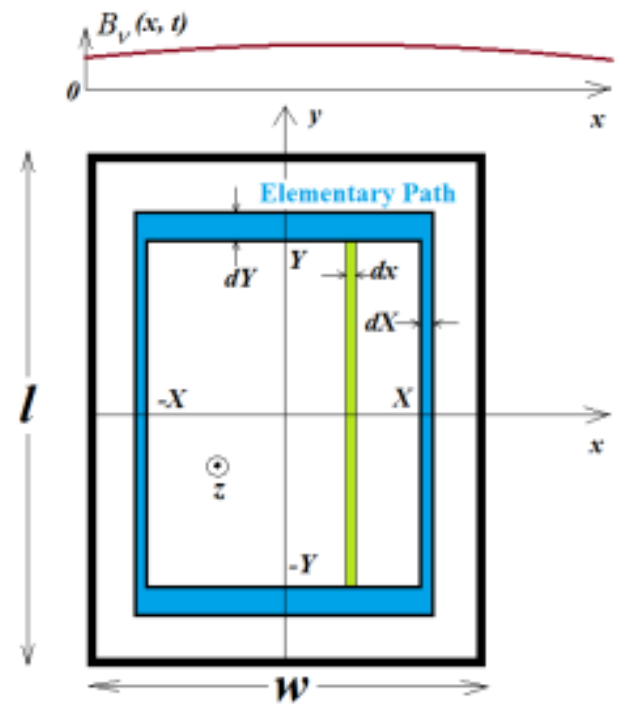

(a): eddy-current elementary path configuration

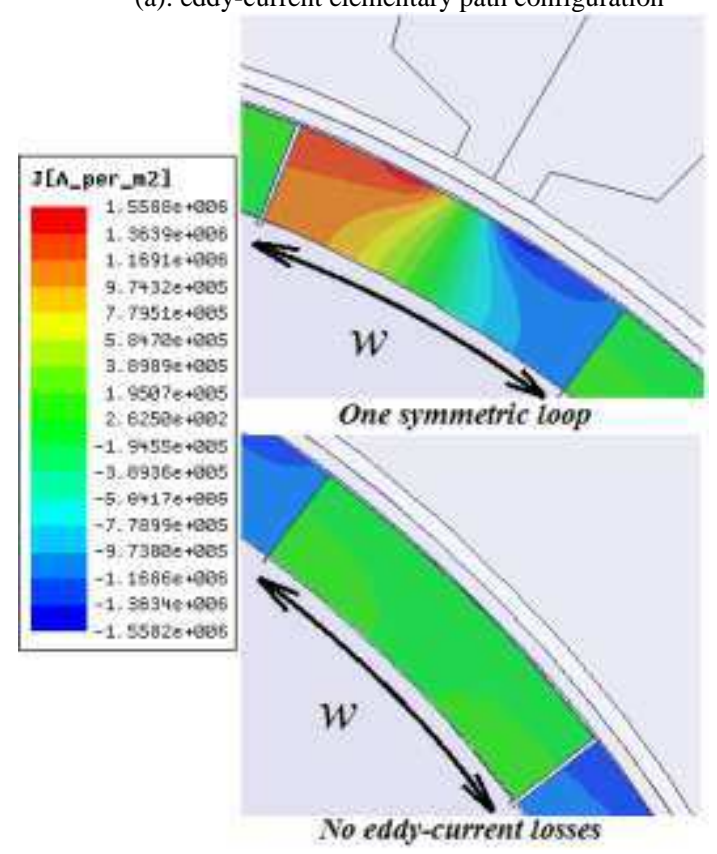

(b): 2D finite elements model of eddy-current density distribution in magnets

Fig. 3 Eddy-current paths when $\lambda_{v} / w>2$
B. Case with $2>\frac{\lambda_{v}}{w}>1$

In this case, eddy-currents paths take a form of asymmetric variables loops where their centers move along the width of magnet pole with the same relative speed as the harmonic $v$ (Fig. 2). This variable situation is a result of a phase shift higher than $180^{\circ}$ in induced current densities along the magnet width. Two symmetric cases are reached while eddy-currents are changing their asymmetric paths. Furthermore, between these two symmetric limits magnet losses vary from maximum to minimum without passing by zero. An example of instantaneous losses in this case is calculated by 2D transient finite elements analysis and shown in Fig. 4 (d). Since losses calculation considering all asymmetric situations is complicated, only two models of current paths which represent the last two symmetric cases are built. Then, total magnet losses are considered equal to the mean value of instantaneous losses at these two limits.

Fig. 4 (a), (b) represents the two symmetric cases of eddy-current loops when $2>\lambda_{v} / w>1$.

At the first symmetric situation losses calculations are the same as in the case $\lambda_{v} / w>2$ where one symmetric loop model is always valid. This situation takes place because of two identical regions of induced current density but with opposite directions. However, in the case of $2>\lambda_{v} / w>1$ this model is not valid at any time but only when $\omega_{v} t=\pi \cdot k: k \in I N$ (see Fig. 4 (a)). Thus, using equation (3), the instantaneous value of elementary path Joule losses when passing by one loop symmetric situation is equal to:

$$
d P_{e}=\frac{\alpha^{3} \cdot e \cdot B_{v}{ }^{2} \cdot \omega_{v}{ }^{2} \cdot \lambda_{v}{ }^{2} \cdot X}{\pi^{2} \rho\left(\alpha^{2}+1\right)} \times \sin ^{2}\left(\frac{2 \pi}{\lambda_{v}} X\right) \cdot d X
$$

Then, instantaneous magnet volume losses in the first symmetric situation of case (B) become:

$$
\begin{aligned}
& \left(\left[\left(P_{v o l}\right)_{v}\right]_{b}\right)_{S 1}=\frac{\alpha^{2} B_{v}{ }^{2} \omega_{v}{ }^{2}}{2 \cdot \pi^{2} \rho\left(\alpha^{2}+1\right)} \times \\
& {\left[\frac{\lambda_{v}{ }^{2}}{8}+\frac{\lambda_{v}{ }^{4}}{16 \cdot \pi^{2} w^{2}}\left(1-\cos \left(\frac{2 \pi}{\lambda_{v}} w\right)\right)-\frac{\lambda_{v}{ }^{3}}{8 \cdot \pi \cdot w} \sin \left(\frac{2 \pi}{\lambda_{v}} w\right)\right]}
\end{aligned}
$$

The second symmetric situation takes the form of two asymmetric current loops (according to their centers). Each loop is a result of two regions of induced current density with opposite directions and with different width. Accordingly, each elementary path in this loop is represented with two asymmetric length sides. The wide side (go path) is proportional to the wide region of positive flux density while the narrow side (return path) is proportional to the negative narrow one (Fig. 4 (b)).

The global narrow side of the loop is situated on 
the edge of magnet pole with a width of $\frac{w}{2}-\frac{\lambda_{v}}{4}$ while the thick one is situated in the middle with the width of $\frac{\lambda_{v}}{4}$ (see Fig. 4 (b)). Thanks to the symmetry in situation 2, it will be enough to calculate instantaneous magnet volume losses only in one of these two loops. However, chosen elementary current paths should respect the asymmetry imposed by the whole loop.

Fig. 4 (b) represents the coordinates of each asymmetric elementary path according to the loop center (coordinates center). It can be noticed that elementary paths model is structured in order to scan the asymmetric loop keeping the same center. Hence, when $X=\frac{w}{2}-\frac{\lambda_{v}}{4}$ (the biggest elementary path) the left side of the path becomes equal to $-\frac{\lambda_{v}}{4}$ allowing to cover the entire loop.

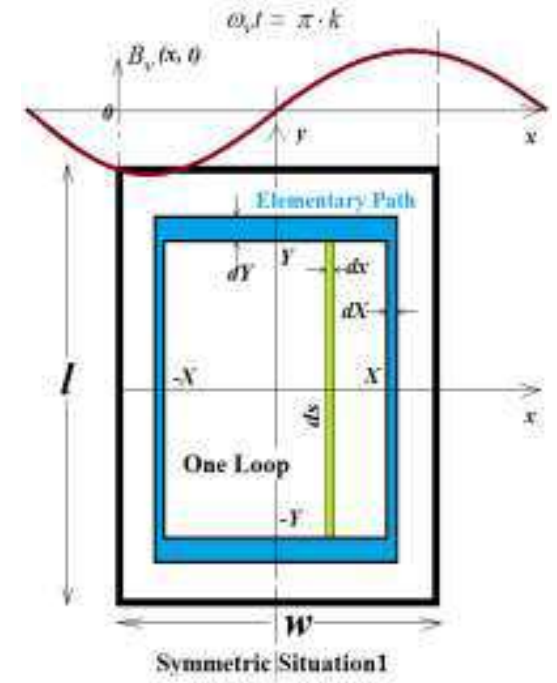

(a): first situation of eddy-current elementary path configuration

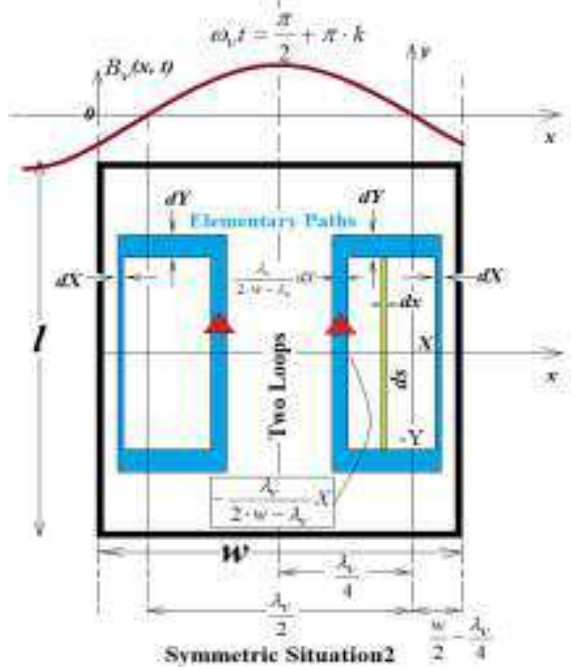

(b): second situation of eddy-current elementary path configuration

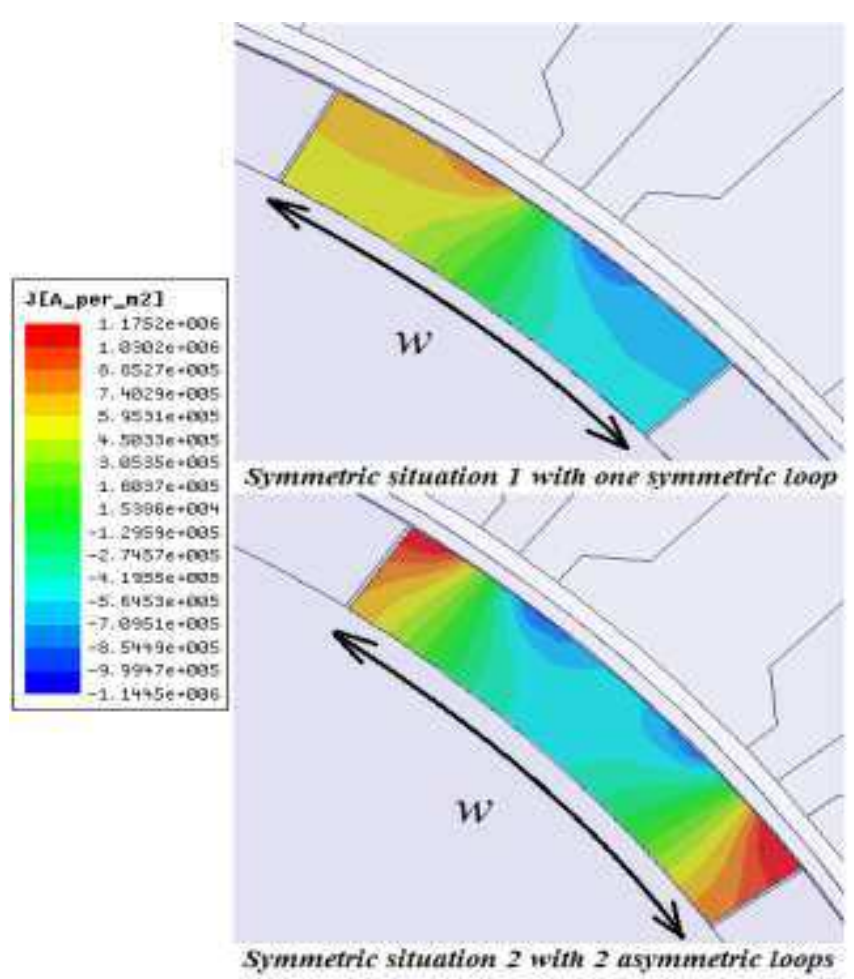

(c): 2D finite elements model of eddy-current density distribution in magnets

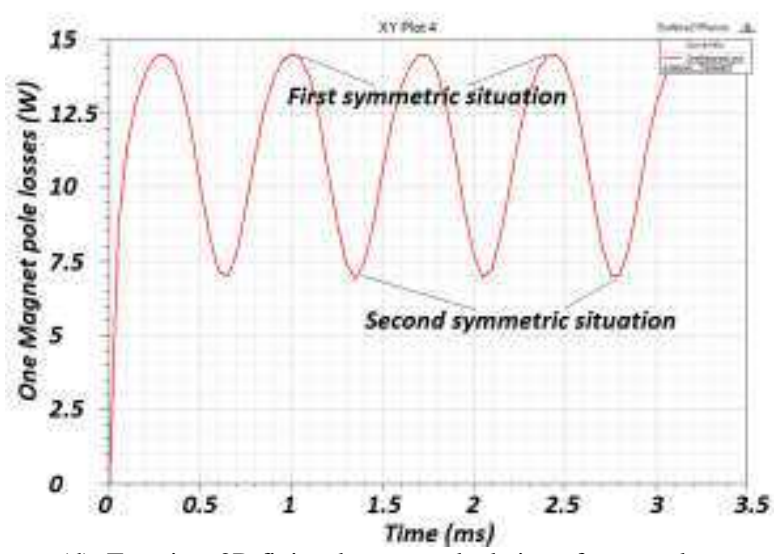

(d): Transient 2D finite elements calculation of magnet losses

Fig. 4 the two limit symmetric situations for eddy-current paths when $2>\lambda_{v} / w>1$

2D finite elements simulations of eddy-current density distribution at the two symmetric situations are illustrated in Fig. 4 (c).

After moving the reference of coordinates to the center of the right loop, magnetic flux captured by one elementary eddy-current path $(X, Y)$ can be written:

$$
\begin{aligned}
& \Phi_{e}=\int_{-\frac{\lambda_{v}}{2 \cdot w-\lambda_{v}} X}^{X} B_{v}(x, t) \cdot d s: d s=2 \cdot \frac{2 \cdot w}{2 \cdot w-\lambda_{v}} \cdot \alpha \cdot X \cdot d x \\
& B_{v}(x, t)=B_{v} \cdot \sin \left(\omega_{v} t+\frac{2 \pi}{\lambda_{v}} x+\frac{\pi}{2}\right) \\
& \alpha=\frac{2 \cdot w-\lambda_{v}}{2 \cdot w} \cdot \frac{Y}{X}=\frac{l}{w}
\end{aligned}
$$


$\Phi_{e}(X, t)=\frac{4 \cdot w \cdot \alpha \cdot X \cdot B_{v} \cdot \lambda_{v}}{\pi \cdot\left(2 \cdot w-\lambda_{v}\right)} \sin \left(\frac{2 \cdot w}{\left(2 \cdot w-\lambda_{v}\right) \cdot \lambda_{v}} \pi \cdot X\right)$

$\times \sin \left(\omega \cdot t+\frac{\pi}{2}+\frac{2 \cdot\left(w-\lambda_{v}\right)}{\left(2 \cdot w-\lambda_{v}\right) \cdot \lambda_{v}} \pi \cdot X\right)$

Since the presented eddy-current paths model is validate only for the second instantaneous symmetric situation, magnet losses should be calculated at the instants $\omega_{v} t=\frac{\pi}{2}+\pi \cdot k: k \in I N$, which leads to:

$\left[\left(\frac{\partial \Phi_{e}(X, t)}{\partial t}\right)_{\varpi \cdot t=\pi / 2+\pi \cdot k}\right]^{2}=\frac{16 \cdot w^{2} \cdot \alpha^{2} \cdot X^{2} \cdot B_{v}{ }^{2} \cdot \lambda_{v}{ }^{2} \cdot \omega_{v}{ }^{2}}{\pi^{2} \cdot\left(2 \cdot w-\lambda_{v}\right)^{2}}$ $\times \sin ^{2}\left(\frac{2 \cdot w}{\left(2 \cdot w-\lambda_{v}\right) \cdot \lambda_{v}} \pi \cdot X\right) \cdot \cos ^{2}\left(\frac{2 \cdot\left(w-\lambda_{v}\right)}{\left(2 \cdot w-\lambda_{v}\right) \cdot \lambda_{v}} \pi \cdot X\right)$

Electrical resistance $R_{e}$ of an elementary eddy-current path depends on the path configuration which is variable with time. This resistance $R_{e}$ at the second symmetric situation is calculated:

$$
\begin{aligned}
& \left(R_{e}\right)_{\omega \cdot t=\pi / 2+\pi \cdot k}=\rho \cdot \frac{2 \cdot X \cdot \frac{2 \cdot w}{2 \cdot w-\lambda_{v}}}{e \cdot d Y}+\rho \cdot \frac{2 \cdot Y}{e \cdot d X} \\
& +\rho \cdot \frac{2 \cdot Y}{e \cdot \frac{\lambda_{v}}{2 \cdot w-\lambda_{v}} d X} \Rightarrow \\
& \left(R_{e}\right)_{\omega \cdot t=\pi / 2+\pi \cdot k}=\rho \cdot \frac{2 \cdot X\left[1+\frac{4 \cdot \alpha^{2} \cdot w^{2}}{\left(2 \cdot w-\lambda_{v}\right) \cdot \lambda_{v}}\right]}{e \cdot \alpha \cdot d X}
\end{aligned}
$$

Now, instantaneous Joule losses in an elementary current path can be deduced:

$$
\begin{aligned}
& d P_{e}=\left(\frac{\left(\frac{\partial \Phi_{e}(X, t)}{\partial t}\right)^{2}}{R_{e}}\right)_{\omega t=\pi / 2+\pi \cdot k} \\
& d P_{e}=\frac{2 \cdot w^{2} \cdot \alpha^{3} \cdot e \cdot B_{v}{ }^{2} \cdot \lambda_{v}{ }^{2} \cdot \omega_{v}{ }^{2}}{\rho \cdot \pi^{2} \cdot\left(2 \cdot w-\lambda_{v}\right)^{2} \cdot\left(1+\frac{4 \cdot \alpha^{2} \cdot w^{2}}{\left(2 \cdot w-\lambda_{v}\right) \cdot \lambda_{v}}\right)} \\
& \times X \cdot\left[\sin \left(\frac{2 \cdot \pi \cdot X}{\lambda_{v}}\right)+\sin \left(\frac{2 \cdot \pi \cdot X}{2 \cdot w-\lambda_{v}}\right)\right]^{2} \cdot d X
\end{aligned}
$$

Then, eddy-current magnet volume losses generated in one current loop of the second symmetric situation of case (B) are calculated:

$$
\left(\left[\left(P_{\text {vol }}\right)_{V}\right]_{b}\right)_{S 2}=\frac{\int_{0}^{\frac{w}{2}-\frac{\lambda_{v}}{4}} d P_{e}}{\text { magnet pole volume }}=\frac{\int_{0}^{\frac{w}{2}-\frac{\lambda_{v}}{4}} d P_{e}}{e \cdot \alpha \cdot \frac{w^{2}}{2}}
$$

$$
\begin{aligned}
& \left(\left[\left(P_{v o l}\right)_{v}\right]_{b}\right)_{S 2}=\frac{\frac{4 \cdot w^{2} \cdot \alpha^{2}}{\left(2 \cdot w-\lambda_{v}\right) \cdot \lambda_{v}} \cdot B_{v}{ }^{2} \cdot \omega_{v}{ }^{2}}{2 \cdot \rho \cdot \pi^{2} \cdot\left(1+\frac{4 \cdot w^{2} \cdot \alpha^{2}}{\left(2 \cdot w-\lambda_{v}\right) \cdot \lambda_{v}}\right)} \times \\
& {\left[\frac{\left(2 \cdot w-\lambda_{v}\right) \cdot \lambda_{v}{ }^{3}}{16 \cdot w^{2}} \cdot\left(1+\frac{2}{\pi^{2}}+\frac{2 \cdot \lambda_{v}{ }^{2}}{\pi^{2}} \cdot\left(\frac{1}{w^{2}}-\frac{1}{\left(w-\lambda_{v}\right)^{2}}\right)\right)\right.} \\
& +\frac{\lambda_{v}{ }^{4}}{16 \cdot \pi \cdot w^{2}} \cdot \sin \left(\frac{2 \cdot w \cdot \pi}{\lambda_{v}}\right) \\
& +\frac{\lambda_{v}{ }^{5}}{8 \cdot \pi^{2} \cdot w^{2} \cdot\left(2 \cdot w-\lambda_{v}\right)}\left(1+\cos \left(\frac{2 \cdot w \cdot \pi}{\lambda_{v}}\right)\right) \\
& -\frac{\left(2 \cdot w-\lambda_{v}\right)^{2} \cdot \lambda_{v}{ }^{4}}{8 \cdot \pi \cdot w^{3}\left(w-\lambda_{v}\right)} \cdot \sin \left(\frac{w \cdot \pi}{\lambda_{v}}\right) \\
& \left.-\frac{\left(2 \cdot w-\lambda_{v}\right) \cdot\left(2 w^{2}-\lambda_{v} \cdot\left(2 \cdot w-\lambda_{v}\right)\right) \cdot \lambda_{v}{ }^{5}}{8 \cdot \pi^{2} \cdot w^{4}\left(w-\lambda_{v}\right)^{2}} \cdot \cos \left(\frac{w \cdot \pi}{\lambda_{v}}\right)\right]
\end{aligned}
$$

Finally, mean value of magnet volume losses in the case (B) can be identified:

$$
\begin{aligned}
& {\left[\left(P_{v o l}\right)_{v}\right]_{b} }=\frac{\left(\left[\left(P_{v o l}\right)_{v}\right]_{b}\right)_{S 1}+\left(\left[\left(P_{v o l}\right)_{v}\right]_{b}\right)_{S 2}}{2} \\
& \text { C. } \text { Case with } 1>\frac{\lambda_{v}}{w}>\frac{2}{3}
\end{aligned}
$$

This case like the last one is based on variable eddycurrent paths forming symmetric and asymmetric loops. The difference between the two cases is the number of eddy-current loops which may appear where a situation with three current loops can accrue in case (C) (see Fig. 5 (a)). This difference leads towards other two symmetric situations representing other minimummaximum of magnet losses.

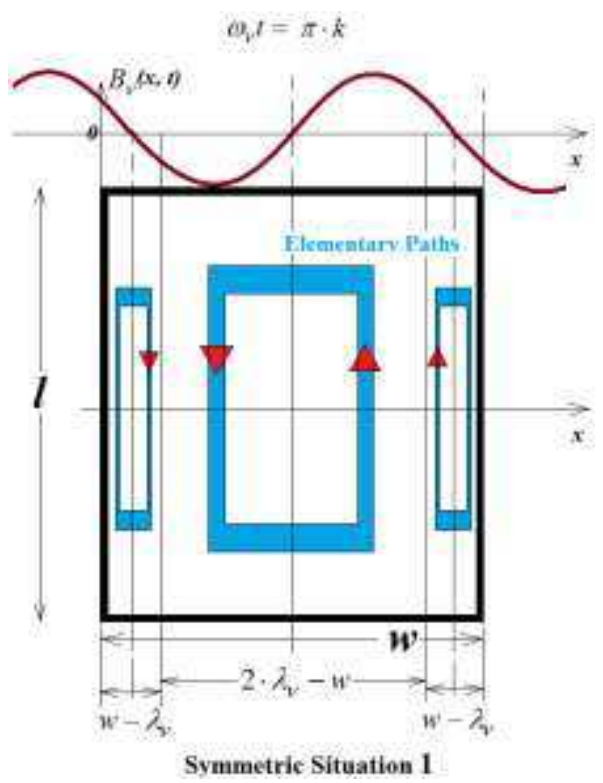

(a): first situation of eddy-current elementary path configuration 


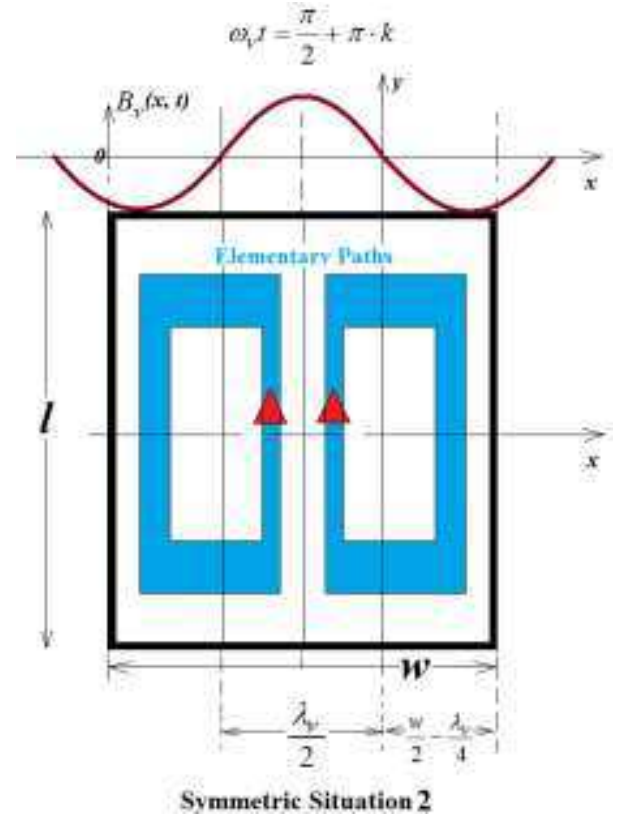

(b):second situation of eddy-current elementary path configuration

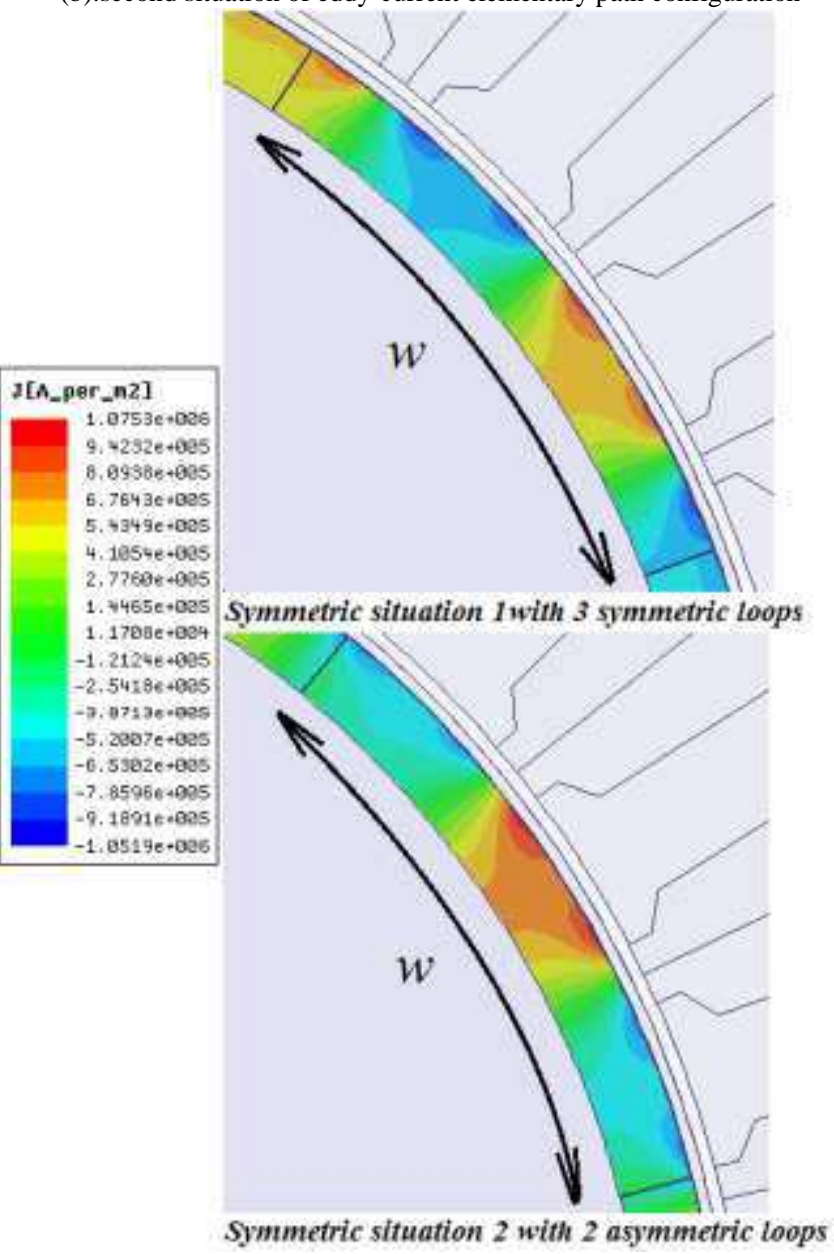

(c): 2D finite elements model of eddy-current density distribution in magnets

Fig. 5 the two limit symmetric situations for eddy-current paths when $1>\lambda_{v} / w>2 / 3$
It can be noticed in Fig. 5 (a) that the first symmetric situation is composed of 3 symmetric loops. Thus, equation (5) can be applied on the middle loop after the replacement of $w$ by $w-\lambda_{v}$ and on the two external loops after the replacement of $w$ by $2 \cdot \lambda_{v}-w$.

$$
\begin{aligned}
& {\left[\left(P_{v o l}\right)_{v}\right]_{\text {ExternalLoop }}=\left(\left[\left(P_{v o l}\left(w-\lambda_{v}\right)\right)_{v}\right]_{b}\right)_{S 1}} \\
& {\left[\left(P_{v o l}\right)_{v}\right]_{\text {MiddleLoop }}=\left(\left[\left(P_{v o l}\left(2 \cdot \lambda_{v}-w\right)\right)_{v}\right]_{b}\right)_{S 1}}
\end{aligned}
$$

As a result, instantaneous magnet volume losses in the first symmetric situation of case $(\mathrm{C})$ can be deduced:

$$
\begin{aligned}
& \left(\left[\left(P_{v o l}\right)_{V}\right]_{c}\right)_{S 1}=\frac{2 \times\left(w-\lambda_{v}\right) \times\left[\left(P_{v o l}\right)_{V}\right]_{\text {ExternalLoop }}}{w} \\
& +\frac{\left(2 \cdot \lambda_{v}-w\right) \times\left[\left(P_{v o l}\right)_{V}\right]_{\text {MiddleLoop }}}{w}
\end{aligned}
$$

The second symmetric situation of the case $(\mathrm{C})$ is formed by two similar but asymmetric loops according to their centers in the same way as in the second situation of case (B) (see Fig. 5 (b)). Consequently, equation (6) can be applied directly in order to obtain instantaneous magnet volume losses in the second symmetric situation of case $(\mathrm{C})$.

$$
\left(\left[\left(P_{v o l}\right)_{V}\right]_{c}\right)_{S 2}=\left(\left[\left(P_{v o l}\right)_{V}\right]_{b}\right)_{S 2}
$$

Finally, mean value of magnet volume losses in the case $(\mathrm{C})$ can be identified:

$$
\left[\left(P_{v o l}\right)_{v}\right]_{c}=\frac{\left(\left[\left(P_{v o l}\right)_{v}\right]_{c}\right)_{S 1}+\left(\left[\left(P_{v o l}\right)_{v}\right]_{c}\right)_{S 2}}{2}
$$

The case $(\mathrm{C})$ is validated as well using 2D finite elements model of current density distribution which shows the presence of the two previous symmetric situations Fig. 5 (c).

$$
\text { D. Case with } \frac{\lambda_{v}}{w}<\frac{2}{3}
$$

While magnet pole width is becoming longer than MMF wavelength, new variable moving eddy-current loops will be generated. Since every added current loop generates locally the same amount of Joule losses as the other loops, the influence of magnet width increasing on total magnet volume losses becomes smaller when it is much longer than MMF wavelengths $w>\lambda_{v}$.

Consequently, no need to consider all possible situations of eddy-current loops but magnet width can be divided into $n$ integer parts where each part has a width $\frac{3}{2} \lambda_{v}$ while the rest $w-n \cdot \frac{3}{2} \lambda_{v}$.

Magnet volume losses are calculated in these equal parts as in the case (C) using equations (6), (8), (9), and (10) after the replacement of $w$ by $3 \lambda_{v} / 2$.

$$
\begin{aligned}
& \left(\left[\left(P_{v o l}\right)_{v}\right]_{d}\right)_{\text {Part }}= \\
& \frac{\left(\left[\left(P_{v o l}\left(w=\lambda_{v} / 2\right)\right)_{v}\right]_{b}\right)_{S 1}+\left(\left[\left(P_{v o l}\left(w=3 \lambda_{v} / 2\right)\right)_{v}\right]_{b}\right)_{S 2}}{2}
\end{aligned}
$$


The rest of magnet pole $w-n \frac{3}{2} \lambda_{v}$ is treated as a new independent magnet piece with a width $w^{\prime}$ which realizes: $0<w^{\prime}<3 \lambda_{v} / 2$. Accordingly, in order to calculate magnet volume losses in the rest of width, stages (A), (B), and (C) can be reapplied.

To conclude, the general equation (for all previous cases) of magnet volume losses resulting from an MMF parasitic harmonic $(v)$ can be identified:

$$
\left[\left(P_{v o l}\right)_{v}\right]=\left[\begin{array}{l}
\text { if } \frac{\lambda_{v}}{w^{\prime}}>2 \\
\frac{w^{\prime} \cdot\left[\left(P_{v o l}\left(w^{\prime}\right)\right)_{v}\right]_{a}+n \cdot \frac{3}{2} \cdot \lambda_{v} \cdot\left(\left[\left(P_{v o l}\right)_{v}\right]_{d}\right)_{\text {Part }}}{w} \\
\frac{w^{\prime} \cdot\left[\left(P_{v o l}\left(w^{\prime}\right)\right)_{v}\right]_{b}+n \cdot \frac{3}{2} \cdot \lambda_{v} \cdot\left(\left[\left(P_{v o l}\right)_{v}\right]_{d}\right)_{\text {Part }}}{w} \\
\frac{w^{\prime} \cdot\left[\left(P_{v o l}\left(w^{\prime}\right)\right)_{v}\right]_{c}+n \cdot \frac{3}{2} \cdot \lambda_{v} \cdot\left(\left[\left(P_{v o l}\right)_{v}\right]_{d}\right)_{\text {Part }}}{w}
\end{array}\right.
$$

while $n=w \operatorname{div}\left(\frac{3}{2} \lambda_{v}\right)$ and $w^{\prime}=w-n \cdot \frac{3}{2} \lambda_{v}$

By observing previous equations, it can be noticed that magnet pole length $l$ can also affect magnet volume losses where it is included in all equations by the ratio $\alpha=l / w$. Nevertheless, in equations (4), (5) the ratio $\alpha$ appears only in the factor $\frac{\alpha^{2}}{\alpha^{2}+1}$ which is almost equal to 1 when $\alpha>1$. This factor is already equal to 0.9 for $\alpha=3$. Consequently, magnet pole length has no effect on the level of magnet volume losses when it is long in comparison with magnet width. If the ratio $\alpha$ is lower than 1 the losses will be reduced simply by the factor $\frac{\alpha^{2}}{\alpha^{2}+1}$. The same judgment can be accepted for equation (6) where instead of $\alpha$ the factor $\frac{\left(2 w / \lambda_{v}\right) \cdot \alpha}{\sqrt{\left(2 w / \lambda_{v}\right)-1}}$ can be found with $\frac{\left(2 w / \lambda_{v}\right)}{\sqrt{\left(2 w / \lambda_{v}\right)-1}} \geq 1$ within used ranges.

By taking into account the last approximation and depending on the global equation (11) Fig. 6 shows how magnet volume losses vary with the different MMF harmonics wavelengths in the case of SPM structure. It can be seen that MMF parasitic harmonics with relatively long wavelength (according to $w$ ) produce more magnet losses than other harmonics. This explains why MMF sub-harmonics $\left(\lambda_{v} / w>2\right.$, case A,) and harmonics close to the fundamental $\left(1<\lambda_{v} / w<2\right.$, case B) have such a negative effect on magnet volume losses.

In the special case where $\frac{\lambda_{v}}{w} \gg 1$, magnet volume losses start to be constant as it can be seen in Fig. 6 . Moreover, the special case of magnet pole losses treated in [13]-[17] when homogeneous flux density distribution is applied (No spatial harmonics), is included in this developed model by making $\frac{\lambda_{v}}{w} \rightarrow \infty$ in equation (4):

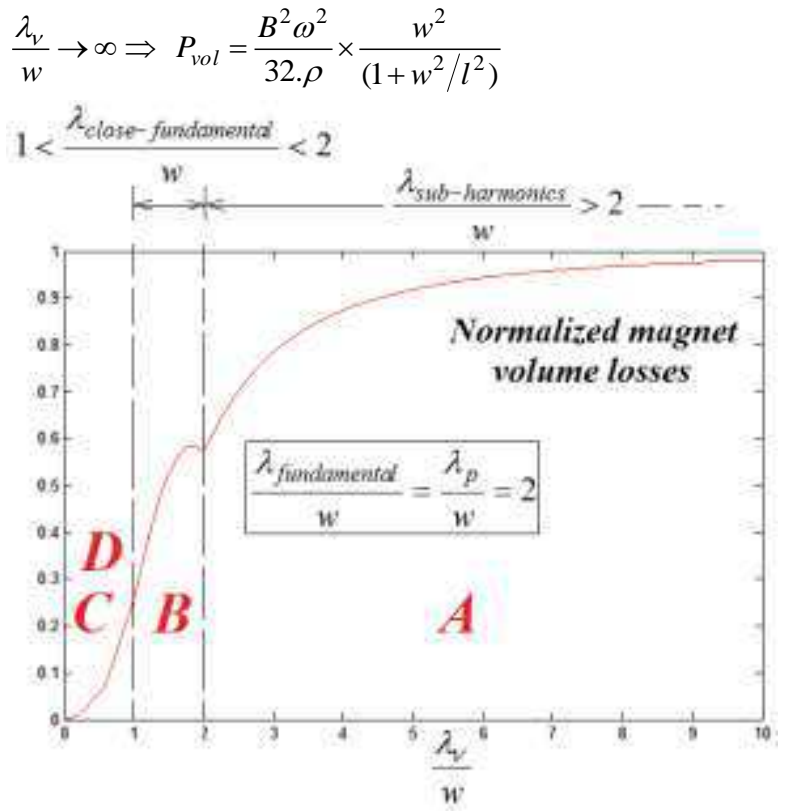

Fig. 6 Impact of the wavelength $\lambda_{v}$ of the MMF harmonics on magnet volume losses in SPM structure (according to the analytical model) for a given $w$ magnet width

Considering all rotating sinusoidal flux density distributions resulting from MMF and assuming the additivity of elementary losses, global magnet volume losses model can be written using equations (11) and (2):

$$
\begin{aligned}
& P_{v o l}=\sum_{v \in\left((M M F)_{\text {spectrum }}\right)}\left[\left(P_{v o l}\right)_{v}\right] \\
& \omega_{v}=2 \cdot \pi \cdot f_{\text {rotor }} p\left|\frac{v}{p}-\mathrm{sgn}\right|
\end{aligned}
$$

IV. Comparison of Slots/Poles configurations for machines with concentrated winding

In this paragraph the analytical model (12) is used to compare magnet volume losses of various Slots/Poles multi-phase machine combinations. The consideration of 3, 5, and 7-phase machines expands the number of possible configurations and allows examining the influence of phase number on magnet losses. Only useful combinations whose winding topologies provide high fundamental or third winding factors are concerned in this study [14]-[18]-[19]. 
The geometry of PM machines may have certain influence on magnet losses [20]. However, the aim of this paper is to examine the influence of winding topologies in different Slots/Poles combinations on magnet volume losses. Hence, the effect of the magnetic structure (materials and geometry) must be neutralized. Therefore, it is supposed that all combinations represent radial flux machines provided with a surface-mounted magnets topology, where the same magnet thickness and the same rotor are considered. Consequently, the difference between combinations according to flux densities $B_{v}$ (resulting from MMF harmonics) in magnets is related mainly to winding topologies and to the injected current. By neglecting iron saturation, these densities $B_{v}$ can be considered proportional to the corresponding MMF harmonics amplitudes $F_{v}$.

$B_{v}=A_{\text {struct }} \times F_{v}$

$A_{\text {struct }}$ : Constant related to the magnetic structure

$F_{v}$ : Amplitude of the harmonic $v$ in MMF spectrum

Equation (13) replaces the flux densities $B_{v}$ in the model by MMF harmonics amplitudes $F_{v}$. These harmonics can be calculated for all combinations using their winding topologies. Where, the fundamental current harmonic is injected with different amplitude, insuring the same linear current density in all combinations. The last hypothesis combined with the unified magnetic structure, allow the combinations to produce the same torque in case of similar winding factors. This makes the magnet losses comparison in different topologies fairer. In Table 1, calculated magnet volume losses are normalized with respect to the lowest value in the case of 5-phase 25/10, considering the same factors $\rho, f_{\text {rotor }}, A_{\text {struct }}$ for all configurations.

Since this paper is concerned by the interaction between MMF wavelengths and magnet width, relatively long machines with non-segmented magnets are considered. This allows neglecting the influence of magnet length and deleting $\alpha$ from the model, as it is explained in paragraph 3 .

In Table 1 three families of combinations can be recognized. A green one with low level of magnet volume losses in which we can find as example the HONDA 3-phase machine 18/12. The combinations of this family are potential candidates for high speed applications (automotive). Moreover, 5-phase combinations which belong to green family generate the lowest magnet losses among all the others. Combinations from the yellow family can be built and run at low and maybe average speeds (TOYOTA 3phase generator 12/8), while red family configurations will probably lead to magnet demagnetization at average speeds because of heating linked to high magnet losses level. In the case of single layer winding, MMF will be structured with a half number of windings. Consequently, more harmful MMF harmonics may appear then more magnet losses are generated. This explains why all combinations of single layer winding in Table 1 belong to the red family.

TABLE I

Normalized magnet volume losses

\begin{tabular}{|c|c|c|c|c|c|c|c|}
\hline Slots/Poles & 4 & 6 & 8 & 10 & 12 & 14 & 16 \\
\hline 6 & 68.2 & - & 198 & - & - & - & 138 \\
\hline 9 & - & 30.4 & 62.6 & 73.3 & 87.8 & - & - \\
\hline 12 & - & - & 16.0 & 75.3 & - & 68.1 & 49.3 \\
\hline 15 & - & - & - & 10.2 & - & 22.5 & 25.1 \\
\hline 18 & - & - & - & - & $\begin{array}{l}7.11 \\
33.0\end{array}$ & 11.9 & 15.1 \\
\hline 21 & - & - & - & - & - & 5.23 & - \\
\hline 24 & - & - & - & - & - & - & 4.01 \\
\hline
\end{tabular}

\begin{tabular}{|c|c|c|c|c|c|c|c|c|c|}
\hline Slots/Poles & 2 & 4 & 6 & 8 & 10 & 12 & 14 & 16 & 18 \\
\hline 5 & 27.7 & 165 & 267 & 263 & & 215 & 185 & 225 & 144 \\
\hline 10 & - & 6.23 & 18.3 & 41.5 & & 66.2 & 71.2 & 65.5 & \\
\hline 15 & - & - & 2.77 & - & & 18.5 & 23.3 & 25.4 & 29.3 \\
\hline 20 & - & - & - & 1.56 & & 4.59 & 26.9 & 9.92 & 26.5 \\
\hline 25 & \multicolumn{7}{|c|}{$5-P h a s e$ Configurations } & & \\
\hline
\end{tabular}

\begin{tabular}{|c|c|c|c|c|c|c|c|}
\hline Slots/Poles & 6 & 8 & 10 & 12 & 14 & 16 & 18 \\
\hline 7 & 96.3 & 130 & - & - & & - & - \\
\hline 14 & 3.70 & 8.21 & 15.0 & 24.3 & & 32.3 & 36.1 \\
\hline 21 & - & - & - & 3.66 & & 16.6 & 10.83 \\
\hline \multicolumn{7}{|c|}{$7-P h a s e$ Configurations } \\
Double Layer Winding Single Layer Winding
\end{tabular}

\begin{tabular}{c|l|c|l|c}
\hline $\begin{array}{c}\text { Red (high } \\
\text { losses) }\end{array}$ & $\begin{array}{c}\text { Yellow(average } \\
\text { losses) }\end{array}$ & & $\begin{array}{c}\text { Green (low } \\
\text { losses) }\end{array}$
\end{tabular}

V. Impact of Magnet Segmentation in Flux Plane on Eddy-Current Volume Losses

One of the important results given by the developed analytical model is the remarkable influence of the ratio $\lambda_{v} / w$ on magnet losses. This fact indicates that, magnet segmentation (into $n_{s}$ segments) in width direction $\left(w \rightarrow w / n_{s}\right)$ can influence magnet volume losses. Obviously, in order to get such an effect on losses, the segments should be electrically isolated. This allows us to see each segment as a new magnet pole.

By considering a specific MMF parasitic harmonic (v) whose wavelength $\lambda_{v}$ is applied on the pole width $w$, the global equation (11) allows calculating the variation of magnet volume losses with the pole 
width. The results are presented in Fig. 7, where the remarkable effect of pole circumferential segmentation (in width direction) on reducing magnet losses can be noticed when $\frac{w}{\lambda_{v}}<1$.

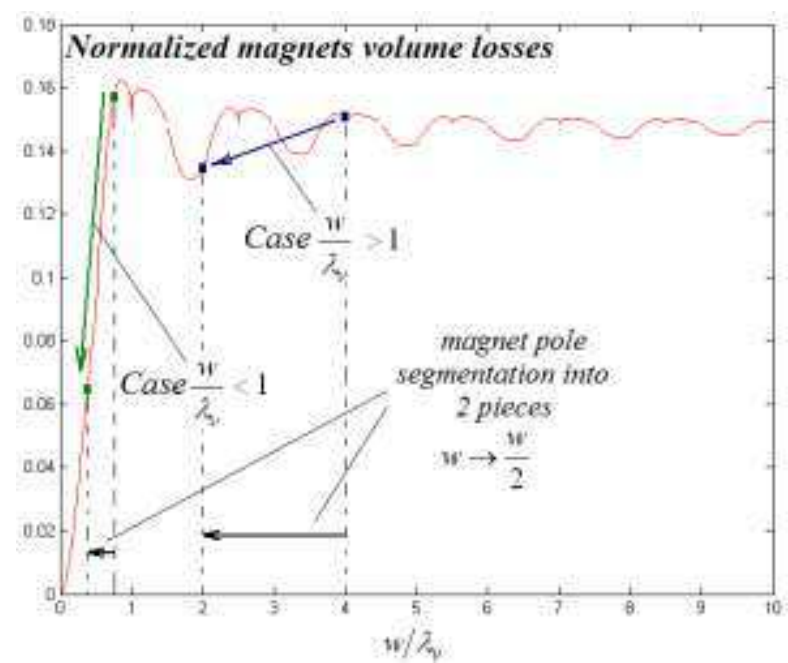

Fig. 7 Impact of pole width on magnets volume losses (according to the analytical model)

\section{Finite Element Validation}

In order to validate the losses analytical comparison presented in paragraph IV, 2D finite elements models of five selected Slots/Poles combinations provided with surface-mounted magnets are built.

These models have the same magnetic structure with the same following parameters: rotor radius, efficient length, air gap and magnet width, linear current density, and total magnets volume. Hence, direct magnet losses comparison is possible.

The 2D finite elements method (FEM) used, allows the circulation of eddy-current in axial direction by imposing a boundary condition of zero average current in each magnet in axial direction.

Thus, the 2D calculus, which cannot take into account the axial segmentation, can be considered as the worst case for each considered Slot/Pole combination.

Of course, a complementary 3D FEM should be necessary in order to consider the impact of axial segmentation on eddy-current losses if a particular structure is considered. Nevertheless, it is reminded that the main aim of this paper is to provide a modeling for comparison of motors with different Slots/Poles combinations and not to provide a precise calculus of losses. Besides, the great impact of circumferential segmentation is then clearly highlighted by considering only a 2D-FEM calculus.

In order to compare the obtained results by $2 \mathrm{D}$ calculation with those of the analytical modeling, it was necessary to consider long structures with a high ratio $\alpha=l / w$ in order to neglect, in the analytical modeling, the influence of magnet length and eddycurrent looping edges which cannot be taken into account in 2D FEM. It can be seen indeed that in these cases, the length is disappearing in the formula (5), (6).

Using FE transient analysis, eddy-current losses are evaluated in magnets as following:

$$
P(t)=\frac{1}{2 \sigma} \cdot\left(J_{a v} \cdot J_{a v}{ }^{*}\right): \quad \vec{J}=-\sigma \frac{\partial \vec{A}}{\partial t}
$$

$P(t)$ : magnet losses at the instant $t, J_{a v}$ : average value of current density in magnet at the instant $t$ (average on 2D surface), $\sigma$ : magnet conductivity, $\vec{A}$ : magnetic vector potential.

Neodymium magnets are used with an electrical resistivity of $180(\mu \Omega \cdot \mathrm{cm})$. Since spatial harmonics of flux density are considered in this study, high mesh density in magnets is adopted. This also allows taking into account the impact of skin effect on magnet losses.

The average value of instantaneous magnet losses is considered in the steady state when the period of losses stabilizes (after $0.5 \mathrm{~ms}$ in the example of Fig. 4 (d)).

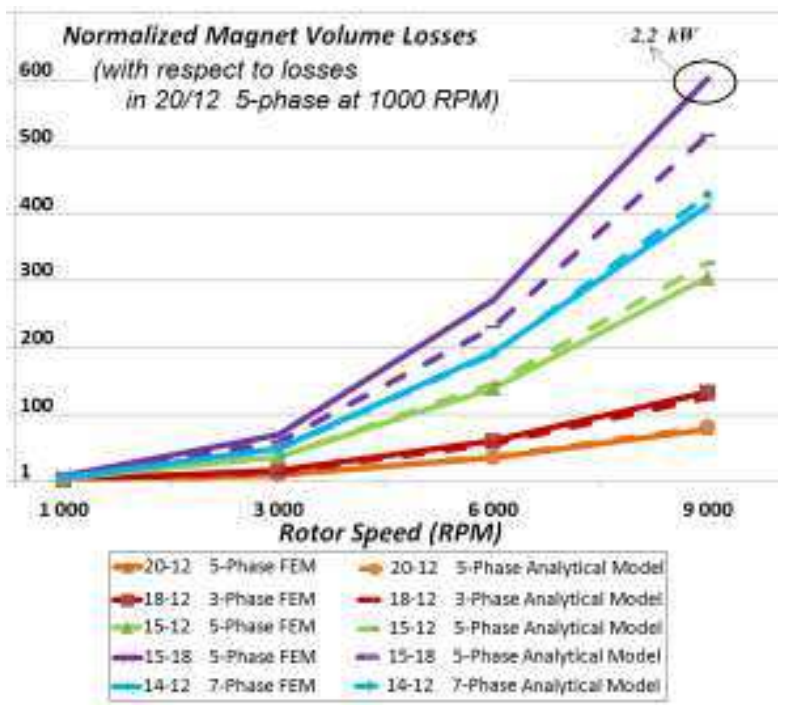

Fig. 8 Normalized magnet volume losses calculated using both finite element method and analytical model (equation 12)

In Fig. 8, normalized finite elements results of magnet volume losses at different rotor speeds are compared with losses given by analytical calculations of Table 1. The topologies and MMF spectrums of these five studied finite elements models are illustrated in [21]. The convergence between FEM and analytical curves shows how the proposed analytical model allows comparing effectively different slot/pole combinations of concentrated winding machines. However, skin effect is not taken into account by the developed analytical model, which may justify the noticeable divergence between FEM and analytical curves at high speeds in the case of 15/18 5-phase 
machine. Especially that, its high poles number leads to high frequencies of flux densities in magnets increasing the influence of skin effect.

In what follows, example of use of paragraph $\mathrm{V}$ results is given.

The analysis of Fig. 8 shows that the combination 5-phase 20 Slots/ 12 Poles is the best one concerning the losses. Nevertheless, in order to still reduce the magnet losses, the harmonics that are at the origin of them are researched. The main parasitic harmonic [21] is $(v=14)$ for this configuration with the corresponding ratio:

$$
\frac{w}{\lambda_{v}}=\frac{\frac{2 \cdot \pi \cdot R_{\text {rotor }}}{2 \cdot p}}{\frac{2 \cdot \pi \cdot R_{\text {rotor }}}{v}}=\frac{v}{2 \cdot p}=\frac{14}{12}=1.16
$$

The Fig. 7 suggests that a circumferential segmentation of each magnet in two isolated pieces could be interesting for reducing the losses. In Fig. 9 (a), the new configuration with the segmentation appears. The ratio is becoming then:

$$
\frac{w}{\lambda_{v}}=\frac{\frac{2 \cdot \pi \cdot R_{\text {rotor }}}{2 \times 2 \cdot p}}{\frac{2 \cdot \pi \cdot R_{\text {rotor }}}{v}}=\frac{v}{4 \cdot p}=\frac{14}{24}=0.58
$$

According to the developed analytical model, the drop in magnet losses due to this segmentation is about $22 \%$ as it can be seen in Fig. 9 (b). In both cases, with and without circumferential segmentation, dynamic magnet losses are also calculated by 2 D-FEM and illustrated in Fig. 9 (c). The comparison between FE and analytical results shows the coherence of the proposed analytical model.

\section{Conclusion}

In this paper new analytical model for comparison of magnet losses in PM machines with concentrated winding is presented. The effect of different MMF spatial harmonics on magnet losses level is investigated. Furthermore, the interaction between wavelengths of these parasitic harmonics and magnet pole dimensions is studied. Then, analytical model of magnet volume losses is developed and generalized using various sub-models in order to cover all possible forms of induced eddy-current paths configuration.

Using this analytical model, magnet volume losses in various combinations of 3,5 , and 7 phase machines are compared between them. Moreover, finite element models are built in order to validate the analytical equations, where simulation results show a good convergence between analytical and FEM calculations.

Thanks to the presented model, magnet volume losses of any Slots/Poles combination can simply be compared, and scaled to losses of another combination depending only on their winding topologies. Consequently, the model can help designers to compare quickly between many winding configurations of electrical machines, then to early exclude bad choices without the need of long and expensive finite element methods FEM. Furthermore, by considering a specific machine structure, sufficiently precise value of magnet volume losses can be calculated using the analytical developed model. Finally, since interaction between MMF spatial harmonics and magnet width is considered by the proposed analytical model, the influence of magnet segmentation in width direction (circumferentially in SPM) on reducing their volume losses is studied, showing a remarkable impact of such a segmentation on eddy-current losses.

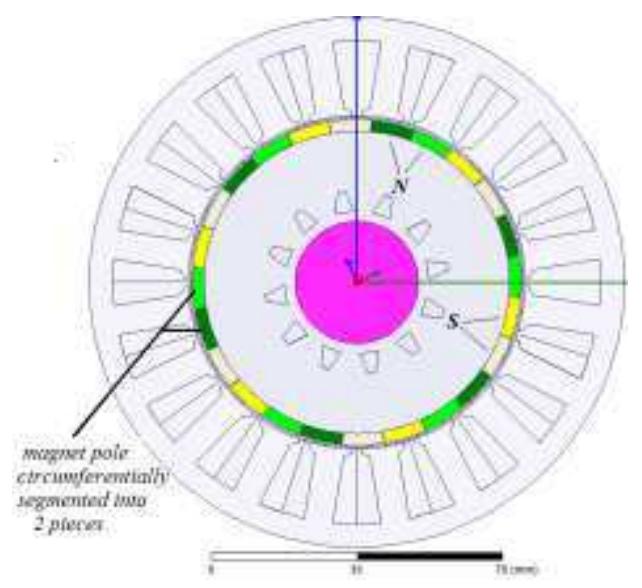

(a) FE model

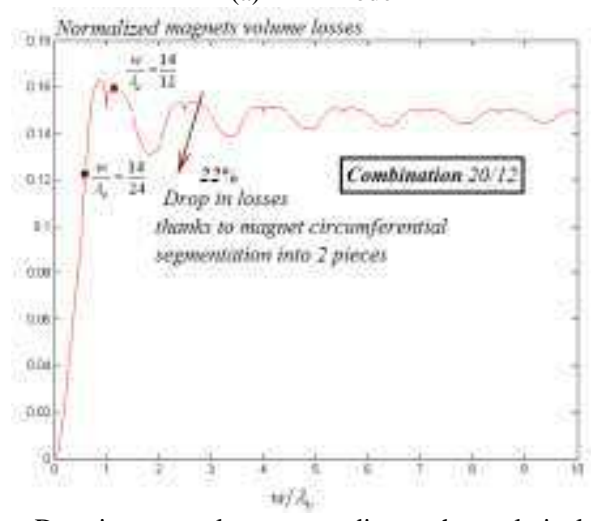

(b) Drop in magnet losses according to the analytical model

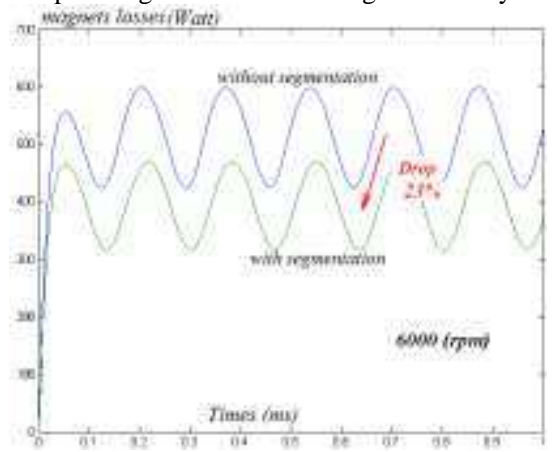

(c) Dynamic magnet losses calculated using 2D finite elements model

Fig. 9 Impact of circumferential segmentation on magnet losses in the 5-phase 20 Slots/ 12 Poles combination 


\section{References}

[1] A.M El-Refaie, "Fractional-Slot Concentrated-Windings Synchronous Permanent Magnet Machines: Opportunities and Challenges", IEEE Trans. on Industrial Electronics, Vol. 57, No. 1, January 2010.

[2] J. Cros, P. Viarouge, "Synthesis of high performance PM motors with concentrated windings" IEEE Trans. on Energy Conversion, vol. 17, no. 2, pp. 248-253, 2002.

[3] F. Magnussen, H. Lendenmann, "Parasitic Effects in PM Machines with Concentrated Windings," IEEE Trans. on Industry Applications, vol.43, no.5, pp.1223-1232, Sept-Oct. 2007.

[4] D. Ishak, Z.Q. Zhu, D. Howe, "Eddy-current loss in the rotor magnets of permanent-magnet brushless machines having a fractional number of slots per pole", Magnetics, IEEE Transaction, vol.41, no.9, pp. 2462- 2469, Sept. 2005.

[5] A.M. El-Refaie, M.R. Shah, Ronghai Qu, J.M. Kern, "Effect of Number of Phases on Losses in Conducting Sleeves of Surface PM Machine Rotors Equipped With Fractional-Slot Concentrated Windings," Industry Applications, IEEE Transaction, vol.44, no.5, pp.1522-1532, Sept.-oct. 2008.

[6] N. Bianchi, S. Bolognani, E. Fomasiero, "A General Approach to Determine the Rotor Losses in Three-Phase Fractional-Slot PM Machines" Proc of IEMDC 07, IEEE International Electrical Machines and Drives Conference, Turkey, 2007.

[7] E. Fornasiero, N. Bianchi, S. Bolognani, "Rotor losses in fractional-slot three-phase and five-phase PM machines", Proc. of ICEM'10, International Conference on Electrical Machines, Italy, Sept. 2010.

[8] Aimeng Wang, Heming Li, Cheng-Tsung Liu, "On the Material and Temperature Impacts of Interior Permanent Magnet Machine for Electric Vehicle Applications" Magnetics, IEEE Transaction, vol.44, no.11, pp.4329-4332, Nov. 2008.

[9] N. Bianchi, E. Fornasiero, "Impact of MMF Space Harmonic on Rotor Losses in Fractional-Slot Permanent-Magnet Machines", IEEE Trans. on Energy Conversion, vol.24, no.2, pp.323-328, June 2009.

[10] Jian Li, Da-Woon Choi, Dong-Hyeok Son, Yun-Hyun Cho, "Effects of MMF Harmonics on Rotor Eddy-Current Losses for Inner-Rotor Fractional Slot Axial Flux Permanent Magnet Synchronous Machines" Magnetics, IEEE Transaction , vol.48, no.2, pp.839-842, Feb. 2012.

[11] T.J.E. Miller, M.I. McGilp, K.W. Klontz, "Approximate methods for calculating rotor losses in permanent-magnet brushless machines", Electric Machines and Drives Conference, 2009. IEMDC '09. IEEE International, vol., no., pp.1-8, 3-6 May 2009.

[12] J. Pyrhonen, H. Jussila, Y. Alexandrova, P. Rafajdus, J. Nerg, "Harmonic Loss Calculation in Rotor Surface Permanent Magnets: New Analytic Approach", Magnetics, IEEE Transaction, vol. 48, no.8, pp.2358-2366, 2012.

[13] Wan-Ying Huang, A. Bettayeb, R. Kaczmarek, J.-C. Vannier, "Optimization of Magnet Segmentation for Reduction of Eddy-Current Losses in Permanent Magnet Synchronous Machine", Energy Conversion, IEEE Transaction, vol.25, no.2, pp.381-387, June 2010.

[14] B. Aslan, E. Semail, J. Legranger, "Slot/pole Combinations Choice for Concentrated Multiphase Machines dedicated to Mild-Hybrid Applications", International Conference on Industrial Electronics 2011, IECON '11, Melbourne Australia, November 7-10 2011.

[15] L.J. Wu, Z.Q. Zhu, D. Staton, M. Popescu, D. Hawkins, "Analytical Model for Predicting Magnet Loss of SurfaceMounted Permanent Magnet Machines Accounting for Slotting Effect and Load" Magnetics, IEEE Transaction , vol.48, no.1, pp.107-117, Jan. 2012.

[16] E. Fornasiero, N. Bianchi, S. Bolognani, "Slot Harmonic Impact on Rotor Losses in Fractional-Slot Permanent-Magnet Machines" Industrial Electronics, IEEE Transaction, vol.59, no.6, pp.2557-2564, June 2012
[17] A. Bettayeb, X. Jannot, J. Vannier, "Analytical calculation of rotor magnet eddy-current losses for high speed IPMSM," Electrical Machines (ICEM), 2010 XIX International Conference on , vol., no., pp.1-6, 6-8 Sept. 2010.

[18] E. Levi, "Multiphase electric machines for variable-speed applications," IEEE Trans. on Industrial Electronics, vol. 55, no. 5, 2008, pp. 1893-1909.

[19] F. Scuiller, J.-F. Charpentier, E. Semail, S. Clenet, "Comparison of two 5-phase Permanent Magnet machine winding configurations. Application on naval propulsion specifications" Electric Machines \& Drives Conference, 2007. IEMDC '07. IEEE International, vol.1, no., pp.34-39, 3-5 May 2007.

[20] L. Alberti, E. Fornasiero, N. Bianchi, "Impact of the Rotor Yoke Geometry on Rotor Losses in Permanent-Magnet Machines" Industry Applications, IEEE Transaction, vol.48, no.1, pp.98-105, Jan.-Feb. 2012.

[21] B. Aslan, E. Semail, J. Legranger, "Analytical Model of Magnet Eddy-Current Volume Losses in Multi-phase PM Machines with Concentrated Winding", IEEE Energy Conversion Congress \& Exposition 2011, ECCE2012, Raleigh North Carolina US, September 15-20 2012. 